\title{
DESVELANDO IMAGENS DE UM SERTÃO 'SECO E DA FOME' E RESSIGNIFICANDO SABERES: A PROPOSTA DA EDUCAÇÃO CONTEXTUALIZADA PARA A CONVIVÊNCIA COM O SEMIÁRIDO BRASILEIRO
}

\author{
UNVEILING OF THE IMAGES OF A SERTÃO 'DRY AND HUNGER "AND \\ REDEFINITION OF KNOWLEDGE: A PROPOSAL OF CONTEXTUALIZED \\ EDUCATION FOR COEXISTENCE WITH BRAZILIAN SEMIARID
}

\author{
Luzineide Dourado Carvalho ${ }^{1}$
}

Resumo: Analisam-se as imagens negativas e preconceituosas sobre a natureza, o território e as gentes do sertão semiárido contidas nos livros didáticos. Apresenta-se a Educação Contextualizada para a Convivência com o Semiárido Brasileiro, agenciada pela RESAB. Dentre outras ações, essa rede atua com a produção de materiais didáticos, reapresentando o Semiárido, com suas belezas e potencialidades. Emergem outros sentidos de pertencimento territorial, ressignificando a mundaneidade e a territorialidade dos sujeitos da ação educativa e provocando novos saberes sobre e no sertão.

Palavras-Chave: Sertão Semiárido. Territorialidade. Educação Contextualizada. Livros Didáticos.

Abstract: Analyzes negative and prejudiced images of nature, the territory and people of the semiarid backlands contained in textbooks. Shows the Contextual Education for Coexistence with the Brazilian semiarid, brokered by RESAB. Among other things, the network works with the production of teaching materials, reaffirming the semiarid region, with its beauty and potential. Other senses belonging to the territory creates a new meaning to the territoriality of the subjects of educational action with new knowledge about the semiarid.

Keywords: Sertão Semiárido. Territorialidade. Educação Contextualizada. Livros Didáticos.

\footnotetext{
${ }^{1}$ Universidade do Estado da Bahia (UNEB), Juazeiro, Docente PPGESA e MPED, Coordenadora do Núcleo de Estudos, Pesquisa e Extensão em Educação Contextualizada para a Convivência com o Semiárido Brasileiro. Email: ldcarvalho@uneb.br
} 


\section{INTRODUÇÃO}

O estudo visa apresentar o sentido da Educação Contextualizada para a Convivência que emana dos processos de articulação e mobilização da Rede de Educação para a Convivência com o Semiárido Brasileiro (RESAB). Uma rede que agrupa diferentes sujeitos, instituições, falas e perspectivas para gerar outro/novo olhar sobre a natureza, o território e as gentes do Sertão Semiárido. Nesse itinerário reflexivo, compreende-se o papel da contextualização nos processos educativos, organizacionais e produtivos e, de como essa metodologia permite a abertura construtivista de conceber a natureza semiárida como uma natureza-processo, cuja seca faz-se parte da própria característica climática dos ambientes semiáridos, e que, portanto, não deve ser combatida.

Problematiza para tanto, as representações sociais negativas e preconceituosas sobre os sertanejos e sua territorialidade. Como denominou Albuquerque Jr. (1999), são dizibilidades e visibilidades construídas em torno dessa região, afirmadas via imagens do cinema, dos discursos parlamentares, da imprensa etc. No artigo aponta-se como os livros didáticos para a Educação Básica também atuam com essa mesma perspectiva discursiva e imagética, fomentando, a partir da Escola e das práticas docentes, a manutenção da estereotipia e a descontextualização dos processos de ensino e aprendizagem.

O percurso teórico-metodológico desse estudo desenvolvido no NEPEC-SAB se apoia nos sentidos dos sujeitos individuais e coletivos (corpo, fala, espacialidade) em sua tomada de consciência com seus contextos existenciais, materiais e simbólicos delineados pela semiaridez, para tanto, a compreensão que se faz de Convivência ancora-se no existencialismo de Heidegger (1981) na busca de apreender que a contextualização pela Convivência com o Semiárido é uma mundaneidade - um sentido ontológico da "solicitude" a um envolvimento significativo dos sujeitos em ser-com-os-outros-no-mundo. Portanto, nesse artigo reflete-se sobre as contribuições possíveis que a Educação Contextualizada pode dar para a elaboração de outra/nova percepção e relação dos sujeitos com o Sertão Semiárido, e assim, valorizando-o como um território diverso, belo e possível. 


\section{TERRITORIALIDADE NO SERTÃO SEMIÁRIDO}

O sertão traz consigo as marcas do processo colonizador das terras brasileiras, refletindo a linguagem do outro, do civilizado. Como enfatiza Almeida (1998: 37), "era uma forma de nomear o desconhecido, expressando o pensamento do europeu sobre o novo continente. $\mathrm{O}$ sertão reforçava o distanciamento entre o eu e o outro".

O sertão ganhou uma paisagem associada à Caatinga, ao Semiárido Brasileiro ${ }^{2}$. Mas, ele não é fechado a essa vegetação e nem um espaço cartografado por fronteiras. Ele é "um conceito complexo, inacabado, em permanente processo de construção, cujas fronteiras ou ausência dessas guardam uma multiplicidade de sentidos e definições" (MENDES, 2009: 69).

Desse modo, o Semiárido é, portanto, um dos tantos 'sertões' presentes na territorialidade desse vasto Brasil. Porém, um território concebido como lugar de repulsa, de estranhamento, de hostilidade, cuja presença da Caatinga, a vegetação predominante, marca sua paisagem, vista como monótona e ao mesmo tempo, agressiva: "De tramas espinescentes", "folhas urticantes" e “gravetos estalados em lança", relata Euclides da Cunha, em Os Sertões (1991).

Tal ambiente, tomado como hostil, foi incorporado à nação brasileira em seu estado nascente, caracterizando a identidade sertaneja pela exclusão sócio-territorial, sendo, desse modo, natureza e homem marcados pela mesma estereotipia: O sertão de homens "apáticos e engessados" (BASSAND, 1999: 110) apud (ALMEIDA, 2005), de tipo humano e seu modo de vida tradicionalmente resignado, vítima da seca, miserável, messiânico, revoltado ou conformado na penúria.

Nesses sentidos expostos, o bioma Caatinga adentra na literatura como um ambiente hostil, marcado pela pobreza de espécies e em endemismos. Tal perspectiva equivocada ainda se faz presente na atualidade, destacando-se nos livros didáticos e na forma como se apresenta essa vegetação. Para Almeida (2007), são concepções que se reportam à Caatinga como um lugar de exclusão sócio territorial onde habitam e sobrevivem precariamente os Caatingueiros (as). A afirmativa da autora se reforça no trecho extraído de um paradidático de Geografia:

\footnotetext{
${ }^{2}$ Por ser composto por 11 estados brasileiros (Bahia, Sergipe, Alagoas, Pernambuco, Paraiba, Maranhão, Piaui, Rio Grande do Norte, Ceará, Minas Gerais e Espirito Santo) o Semiárido tem sido mais considerado como 'Semiárido Brasileiro', especialmente pelas redes de convivência (ASA, RESAB e outras), que atuam diretamente com seus programas socioprodutivos, organizacionais e educaconais neste estados.
} 
A menos de $90 \mathrm{~km}$ do mar [...] vegetam apenas os cactos e arbustos espinhosos e retorcidos. Uma paisagem seca e pobre, contrastando tristemente com o panorama vivo e alegre do mar e das matas que ficaram para trás. [...] O que caracteriza essa vegetação é a sua homogeneidade, isto é, o aspecto sempre igual [...] (BRANCO, 1994: 6-7).

A Caatinga tem sido um ecossistema brasileiro "reduzido a um espaço de sobreviventes e retirantes" (SANTOS, 2005: 77). Mas, ao contrário, "não pode ser entendido como um local feio e inóspito, mas que traz uma beleza e riqueza peculiar, admirada, amada, pelas pessoas que vivem nesses espaços há séculos”. Ele ainda ressalta a identidade sertaneja:

As gentes que habitam as diferentes paisagens geohumanas dessa região do Brasil [...] homens e mulheres do Semiárido vivem em processos simbióticos com o bioma caatinga concentrando-se ao redor de cidades maiores, polos indústrias e perímetros irrigados [...] uma ecologia específica, onde as gentes do sertão relacionam-se de forma sistêmica (SANTOS, 2005: 75-77).

Essas leituras não dimensionaram a complexidade dos espaços geohumanos do Semiárido, mas sim, desqualificaram toda a etnobiodiversidade da Caatinga. Como ressalta-se em Santos (2005: 77): “Um ecossistema brasileiro que não pode ser entendido como um local feio e inóspito, mas que traz uma beleza e riqueza peculiar, admirada, amada, pelas pessoas que vivem nesses espaços há séculos".

A rica diversidade histórica, cultural, econômica, social, política e ambiental do sertão semiárido têm sido destacadas apenas pela negatividade. A interação do sertanejo com a Caatinga tem recebido uma interpretação preconceituosa, na qual a particularidade da existência e da organização socioeconômica do sertanejo com seu meio físico e simbólico, suas singularidades e potencialidades, bem como as revelações nas formas de uso e de vivência desses homens e mulheres com seus recursos naturais e culturais não são expressões valorizadas de pertencimento identitário.

O sertanejo, uma vez absorvido pela natureza semiárida, faz desta o cenário para construir seu imaginário, suas crenças, suas práticas materiais e imateriais com o lugar, com o mundo. Uma territorialidade dimensionada de múltiplos significados vividos entre homem, natureza e cultura. Sentidos estes que podem ser interpretados nas palavras de Bonnemaison (2002: 103): 
"Uma relação secreta e emocional que liga os homens à sua terra e, ao mesmo movimento, funda sua identidade cultural”.

\section{DIZIBILIDADES E VISIBILIDADES CONSTRUÍDAS EM TORNO DO SERTÃO SEMIÁRIDO}

A presença das secas engloba-se na própria dinâmica ambiental das chamadas Terras Secas, que perfaz todas as Zonas Áridas, Semiáridas e Subúmidas do mundo (BRASIL, 2004). Os registros de grandes secas fazem presentes ao longo da história da formação e organização geoeconômica do Semiárido Brasileiro. Entretanto, as secas têm sido comunicadas, apresentadas e representadas pela conotação de hostilidade, de algo atípico. Como denominou Albuquerque Jr. (1999), são dizibilidades e visibilidades construidas em torno dessa região, ou seja, a construção narrativa de falar e apresentar no cinema, nos discursos parlamentares, na imprensa etc., por meio de imagens de calamidade, de pedintes e de retirantes, ritualizando e institucionalizando a vitimação e estereotipia de sua natureza (pobre, feia, adversa, de vegetação 'morta'); do sertanejo (o 'cabeça-chata', o ignorante, a vítima do Sul).

A força dessas narrativas legitimaram a apropriação político-ideológica das secas pelas elites nordestinas, que segundo Albuquerque Jr. (1999), souberam utilizar política e economicamente todas circunstâncias, conjunturas e necessidades de cada momento de seca, mantendose e perpetuando-se por gerações no poder local e regional, barganhando com o poder central as benesses e manipulando os recursos destinados as obras hídricas em tempos de calamidade pública pelas longas estiagens.

Cita Carvalho (2012) que a política de 'combate à seca, mesmo com todo o desgaste dos insucessos, descontinuidades e desperdícios de recursos dos planos, projetos e programas estatais, com propósitos de 'solucionar o problema regional nordestino', chegou até o final do século XX. Entretanto, a transição para o século XXI trouxe novas questões e novos atores sociais para a produção e organização do Semiárido: Novos agenciamentos e arranjos produtivos, provocando a reflexão, o debate e a crítica acirrada sobre a política de 'combate à seca' pelo Estado. 


\section{AS IMAGENS DE UM SERTÃO 'SECO E DA FOME' PRESENTES NOS LIVROS DIDÁTICOS}

Em instituições formadoras, como é a Escola, constata-se a reprodução de imagens e discursos de desqualificação representativa sobre o Semiárido Brasileiro, uma vez que nelas chegam materiais didáticos, em especial, os livros, que são para muitos alunos e professores, a exclusiva leitura e orientação metodológica.

Hoje, o livro didático nada mais é que um grande aliado do professor à sua prática pedagógica; em alguns casos, o único. Na verdade o livro didático surge como uma ferramenta essencial de sistematização da informação, pois ele já traz uma carga de conhecimentos e experiências acumuladas ao longo do tempo (SENA, 2012), corrobora com este pensamento Pereira (2012: 62) apud Sena (2012: 41):

Este, muitas vezes é o único instrumento que o professor conta como apoio em sala de aula. Ao ser assim concebido passa a ter como principal função estruturar o trabalho pedagógico do professor mediante a apresentação, de acordo com as disciplinas, dos conteúdos curriculares estereotipados e engessados por determinada cultura em detrimento de outras.

Ainda segundo Sena (2012), na perspectiva geral dos livros didáticos, as características desse território são apenas climáticas e não delineiam um espaço histórico social ou características próprias de um povo. Além de alguns outros aspectos apresentados, e não exploram e nem discutem questões históricas. No entanto, é demasiadamente explorado o tema da seca, mantendo-a pela leitura de ser 'o estigma do Nordeste'.

Nessas narrativas, aparecem alguns temas correlacionados à seca, tais como: A morte do gado, as perdas da lavoura, as inviabilidades naturais da região. São discursos e imagens reforçados nos livros didáticos, que supervalorizam alguns dados em detrimento de outros. Como diz a autora:

O fato é que o livro didático vem carregado de subjetividades e conteúdos pouco explorados. Uma vez que a sobrecarga de inúmeros assuntos pode atuar em detrimento de fatos históricos que para um ensino que apresente resultados na construção do conhecimento sobre a história do lugar; não só a história de um tempo distante, mas a história que se constrói e reconstrói a cada dia (SENA, 2012: 77). 
Lajolo e Zilberman (1999) apud (SENA, 2012) sugerem que o livro didático pode ser enxergado como o primo pobre da literatura, uma vez que seus textos podem ser superados ou pelo tempo ou pelo avanço educacional do estudante. Mas, no que tange aos contextos do Semiárido Brasileiro, muitas imagens têm sido cristalizadas de forma atemporal.

As imagens utilizadas nesses materais não revelam a dinâmica socio-cultural e sua inserção à própria dinâmica espacial e produtiva ao Brasil e ao mundo. Exemplos são imagens da seca, que mesmo sendo livros publicados na década de 2000, ainda mostram imagens da seca de 1952. De retirantes nordestinos migrando para as grandes cidades, nos anos de 1930, sendo ainda publicadas no inicio do seculo XXI.

Ao se avaliar a dinâmica territorial do Semiárido, observa-se que a cada momento histórico de sua formação, um sentido de natureza e de território foi elaborado, que por sua vez, desencadeou formas de intervenções e do surgimento de atores sociais para efetivar os agenciamentos nas escalas espaciais conforme o "meio técnico-científico informacional" de cada época (SANTOS, 1994: 10). Desse modo, se no passado colonial, havia as interações da elite local para o centro do poder (Metrópole; sede da Colônia; Capital Federal), no atual processo de globalização, as relações do Semiárido acontecem entre o local/território com o global. Essas interações globalizadas têm gerado diferentes sentidos tanto de natureza semiárida e suas possibilidades de uso, quanto sentidos de desenvolvimento territorial em disputa (CARVALHO, 2012).

Se essa dinâmica territorial é diversa e complexa, ela por sua vez não é acompanhada nos materiais didáticos e nem nas imagens as revelam. Os conceitos disseminados pela mídia, pelos livros didáticos e reforçados na escola mantêm-se como veracidades imutáveis. Nessa perspectiva, o conceito de Semiárido, é compreendido como sinônimo de clima, de seca e de miséria.

Reis (2010) amplia essa reflexão ao afirmar que ausência desses aspectos nas formações, educadores não passam por transformações sucessivas em seu trabalho, não se reciclam, ficando fechados no conhecimento que já possuem, crendo que seja o suficiente para se trabalhar.

O que se avalia é que os livros didáticos ainda não possibilitam um destaque que permita aos educandos se reconhecerem, ou até mesmo, se afirmarem positivamente como sujeitos do seus espaços e contextos especificos, pois nestes materiais, o espaço geográfico é posto como atemporal, neutro e desarticulado. Como reflete Sena (2012): 
Os livros didáticos precisam permitir a desmistificação de que no Sertão falta água, pois como pode chegar tanta água para os projetos de irrigação se os autores dos livros afirmam que o Sertão é seco? Essas questões precisam ser postas no livro e só um livro pautado na perspectiva da realidade local pode abarcar questões do cotidiano do aluno, pois infelizmente os livros ainda teimam em comparar aspectos do Nordeste a aspectos de outras regiões brasileiras, colocando-o sempre a dadas comparações em situações com outras regiões (SENA, 2012: 80).

Certo que o sertão semiárido, as condições do viver e sobreviver neste vasto território configurado pela irregularidade de chuvas não é nada fácil, e no qual água e território fazem-se uma relação de territorialidade, mas também, de muitas contradições sócio políticas. Entretanto, faz-se necessário desmistificar os discursos embutidos nas imagens acerca deste lugar. E, nessa tarefa, muitas organizações da sociedade civil, constituídas em redes sociais, estão se mobilizando e articulando a ideia de 'Convivência com o Semiárido Brasileiro'. Sobre estas desconstruções em processo é que o item a seguir vai discutir e, em seguida, apresentar a proposta educativa pela contextualização, como forma cultural e subjetiva de reconstruir os saberes em torno do sertão semiárido.

\section{OS NÓS TECIDOS PARA CONSTRUIR A PROPOSTA DA CONVIVÊNCIA COM O SEMIÁRIDO BRASILEIRO}

A sociedade civil organizada no Semiárido Brasileiro assumiu nas duas últimas um papel pró-ativo, pressionando a democratização e o controle social dos programas de desenvolvimento para este território. Um contexto de mudança que se inicia na década de 1980, por meio da abertura política do país. Surgiu nesse período o Movimento Muda Nordeste, apontando a situação de exclusão da região Nordeste e suas lideranças denunciavam as iniquidades sociais históricas. Lançava-se a ideia O Nordeste é viável (FÁVERO, 2002, grifo meu).

Nos anos de 1990 ampliam-se as articulações e dá-se a criação e fortalecimento de sindicatos rurais, associações, cooperativas e Organizações Não-Governamentais. Neste período surge uma importante rede, que é a Articulação no Semiárido Brasileiro (ASA), em 1999, aglutinando várias organizações sociais em torno da proposta da 'Convivência com o Semiárido’. Essa ideia-projeto direciona-se para outro/novo sentido de desenvolvimento territorial, com políticas públicas de inclusão social, de equidade e prudência com os recursos naturais. 
Além da ASA, surge em 2000 a Rede de Educação para a Convivência com o Semiárido Brasileiro (RESAB) e outras redes menores. Essas redes passam a atuar na desconstrução dos significados de estereotipia e negatividade, solidificados sobre natureza, o campo, sociedade, cultura, etc., das 'gentes' do sertão Semiárido. O foco de ação é gerar novas formas de sociabilidade, de tecnologias sociais produtivas e educacionais, possibilitando que, a partir de uma nova base de conhecimentos e práticas sobre a natureza e o território Semiárido se estabeleçam formas de viver e de produzir adequadas e adaptadas às condições de semiaridez.

\section{A TRAJETÓRIA DA RESAB NA CONSTRUÇÃO DA EDUCAÇÃO CONTEXTUALIZADA PARA A CONVIVÊNCIA COM O SEMIÁRIDO BRASILEIRO}

A RESAB surge a partir de iniciativas produtivas e educativas de muitas Organizações Não-Governamentais, das Igrejas, e de Secretarias e algumas Universidades Públicas que vinham desenvolvendo experiências metodológicas para dar outra significação à Educação ofertada no Semiárido. As inflexões curriculares passavam a ser orientadas "para fazer a escola vincular-se às formas de vida e às problemáticas existentes dessa região" (RESAB, 2004).

Os eventos que antecederam a formação da RESAB foram o "Simpósio Escola e Convivência com a Seca", em 1998, e o "I Seminário de Educação no Contexto do Semiárido Brasileiro", em 2000, ambos realizados em Juazeiro/Bahia. O primeiro promoveu a reunião das instituições e das experiências, enquanto no segundo firmou-se o Protocolo de Compromisso pelas instituições presentes, fundando propriamente a rede.

A RESAB, atualmente congrega centenas de Instituições Governamentais (Universidades Federais e Estaduais, Secretarias Estaduais e Municipais de Educação), diversas ONGs, Agências de Cooperação Técnica. A rede conta com o apoio dos Ministérios da Educação (MEC), Meio Ambiente (MAM) e do Desenvolvimento Agrário (MDA). Além de firmar importantes parcerias com instituições de Pesquisa, a exemplo do Instituto Nacional do Semiárido Brasileiro (INSA).

A concepção dos processos educativos da 'Convivência' comungada pela RESAB dimensiona-se para e a partir da produção do conhecimento contextualizado, ou seja, "que a partir do contexto possa articular os diversos saberes/conhecimentos produzidos pela humani- 
dade, objetivando a melhoria das condições de vida no Semiárido Brasileiro" (RESAB, 2004). Neste sentido, a rede atua com quatro referências teórico-práticas: A Gestão Compartilhada, o Currículo Contextualizado, a Formação Continuada e a produção de materiais didáticos e paradidáticos contextualizados, cujo proposito é gerar para crianças, jovens, homens e mulheres do Semiárido uma Educação significativa, que retrate sua realidade.

Para tanto, se faz necessário atuar sobre os materiais didáticos, uma que estes são produzidos, especialmente, no Centro-Sul do país. Materiais como já analisados, são compostos de conteúdos pejorativos, limitados, que reforçam a negatividade e a marginalização do Semiárido diante dos demais territórios brasileiros. Os programas e livros didáticos que chegam até as escolas públicas do Semiárido não contribuem para o desenvolvimento de competências e habilidades das crianças e jovens ou de dotá-los de posicionamentos críticos a respeito das problemáticas enfrentadas ou de posturas criativas para desenvolver soluções prudentes e de respeito às condições de semiaridez. Pelo contrário, não têm gerado impactos positivos na melhoria das condições de vida dos grupos humanos que habitam este vasto território, cuja população equivale a quase $15 \%$ da total do país.

Nas "Diretrizes da Educação para a Convivência com o Semiárido Brasileiro", elaboradas na I Conferência Nacional da RESAB (I CONESA), realizada de 17 a 20 de maio de 2006, em Juazeiro (BA), as propostas provindas das Conferências Estaduais (realizadas entre os anos de 2004 a 2006), foram afirmadas pelos 340 participantes de organizações governamentais e não governamentais, que se faz preciso a garantia do acesso e qualidade da Educação Pública e do respeito à diversidade e especificidades do Semiárido Brasileiro, consolidando a Educação Contextualizada como instrumento indispensável na promoção do desenvolvimento humano sustentável para esse território.

A Educação no Brasil, e em especial, no Semiárido Brasileiro tem a tarefa complexa e desafiante de reverter o péssimo quadro no desempenho do ensino e aprendizagem, de repensar a função e o lugar da Escola. No Semiárido Brasileiro, as escolas, em sua maioria, funcionam de maneira precária, condições que se intensificam nas escolas do campo. A ausência de uma política de formação inicial e continuada para educadores e educadoras que contemple a discussão sobre os contextos naturais, históricos e culturais do Semiárido, aspecto este que demonstra um despreparo e uma falta de conhecimento apropriado sobre quem é o Semiárido por parte dos professores. 
Outro aspecto desafiador é repensar o currículo, uma vez que este ainda se apresenta desarticulado da realidade e propagador somente das vulnerabilidades e negatividades do Semiárido ( $\mathrm{RESAB}, 2006)$.

Ao conceber o campo pedagógico e das aprendizagens fundamentadas na Educação Contextualizada como percurso para outro/novo projeto societário, a ideia é que o conhecimento trabalhado na escola assuma uma dimensão de socialização e emancipação do homem e da mulher do Semiárido e extrapole as dimensões da escola e dos saberes nela trabalhados como algo suficiente em si para a construção da cidadania e de um novo projeto social para o Semiárido (MARTINS e REIS, 2004).

A proposta político-pedagógica dessa rede é uma construção coletiva entre a sociedade civil e o Estado. Ela barganha espaços de poder dentro dos programas do Estado, a fim de que a ECSAB seja implementada como política pública. Um dos percursos tem sido a articulação com o Ministério da Educação e Cultura (MEC) para o reconhecimento e adoção do Livro Didático: "Conhecendo o Semiárido I e II" em todas as escolas públicas municipais de Ensino Fundamental I. Desse modo, gradativamente, a proposta tem sido inserida nos espaços de debate e assumida como uma das propostas centrais da 'Convivência', além da RESAB e da rede Articulação no Semiárido Brasileiro, também por outras redes e atores sociais.

\section{A CONSTRUÇÃo de UM ITINERÁRIO PEDAgógICO CONTEXTUALIZAdO PARA A RESSIGNIFICAÇÃO DOS SABERES}

Nos espaços não formais desenvolve-se um trabalho educativo com o uso de materiais paradidáticos, elaborados no geral, pelas próprias organizações: São cartilhas, folders, vídeos, CDs, DVDs, jogos, etc. O propósito desses materiais é proporcionar um conteúdo conceitual e visual diferente dos materiais didáticos e paradidáticos tradicionais e oficiais.

Nos espaços formais, tais como Escolas e Universidades, a ECSAB vai adentrando no Projeto Político-Pedagógico, referenciando-se na concepção de Currículo Contextualizado, como forma de superar o modelo de Currículo estabelecido pela educação universalista, cujo conhecimento se pauta na neutralidade, na cientificidade e na fragmentação dos conteúdos. A contextualização do conhecimento nos espaços formais apresenta-se em um processo mais 
pontual. O que se observa são algumas Escolas ou Secretarias (municipais/estaduais), que tomam esse itinerário pedagógico como forma de realizar atividades a partir da vivência e do cotidiano dos alunos, tendo como ferramentas práticas motivadoras, por exemplos, a "horta pedagógica", o "estudo da realidade", dentre outras.

As atividades citadas visam integrar os fazeres cotidianos e comunitários dos alunos com os conteúdos disciplinares, motivando-os a pensar na comunidade, a conhecer melhor a realidade que o cercam e possibilitando-os conhecerem suas histórias, suas geografias e seu ambiente sociocultural e ambiental. A Escola torna-se o lugar da descoberta, do fazer-aprender-fazer, pois os alunos após um "estudo da realidade" desenvolvem atividades interdisciplinares, sistematizam o conhecimento adquirido, elaboram e reelaboram conceitos e depois, dão retorno à própria comunidade visitada, que recebe o relatório elaborado pelos alunos, constando suas impressões, percepções e saberes desenvolvidos.

Outra diferença significativa é que por meio da contextualização do saber as crianças e jovens passam a reconhecer os ambientes semiáridos nos materiais didáticos e paradidáticos. Ou seja, elas se reconhecem como partes desse universo apresentado no conteúdo e nas imagens dos livros, e sentem-se sujeitos históricos, produtores de opiniões, de criticidade e de criatividade. Como postulam Martins e Reis:

A Escola é o espaço privilegiado de trocas de conhecimentos e saberes e de
construção de novos referenciais. Nesse sentido, concebemos a escola como
um lugar com cor e sabor, onde as opiniões e as ideias mais avançadas e
mais simples possam buscar o norteamento da compreensão do mundo, das
pessoas e das coisas, sendo que nesse espaço, todos são sujeitos do conheci-
mento e da aprendizagem (MARTINS e REIS, 2004: 10).

A contextualização ao adentrar nos programas e práticas da 'Convivência' motiva e proporciona aos sujeitos o reconhecimento de sua mundaneidade (HEIDEGGER, 1981) e territorialidade sertaneja. Ele passa a compreender e intervir na complexidade das manifestações do seu território, e dessa inserção na trama complexa e diversa do sertão semiárido, esse sujeito pode encontrar as saídas e alternativas diante das problemáticas socioeconômicas e vislumbrar perspectivas para a produção de sua existência no mundo. 


\section{CONSIDERAÇÕES FINAIS}

O aprendizado das especificidades, fragilidades e potencialidades do sertão semiárido é trabalhado na Educação Contextualizada e adentra nos espaços escolares e não escolares, rompendo com narrativas limitantes, desconectadas da complexidade que marca a territorialidade dos sertanejos e sertanejas. A compreensão de que esse território é apenas uma unidade fitoclimática marcada pelas secas, tal leitura desconsidera toda a pluralidade e as múltiplas dimensões materiais e imateriais que o atravessam. No entanto, ao se dimensionar o Semiárido em seus diversos contextos, outra leitura de território emerge e possibilita visualizar a forte interação que se manifesta na relação dessas gentes com sua natureza, marcada pela semiaridez.

A dimensão imaterial, subjetiva e simbólico-cultural do território Semiárido adentra nas práticas, ações, experiências e programas advindos da proposta 'Convivência com o Semiárido Brasileiro'. Um processo cultural-educativo contextualizado nos programas e práticas no qual os sujeitos têm ressignificado os sentidos de natureza e de território, elaborando outros/novos signos e emblemas da identidade territorial sertaneja. Isso vale dizer que os elementos físicos, culturais e simbólicos, os regimes de signos e as subjetividades que compõem o território Semiárido vão emergindo e daquele território fadado como 'o sertão seco e da fome' passa-se ao território de possibilidades de práticas e de vida.

Essa nova lógica de ver, perceber e conceber natureza e território aponta a necessidade de qualificar os sujeitos e as instituições para agirem com a lógica da Convivência. É um processo de mudança cultural. Nesse sentido, tem-se o relevante papel a ser destacado pelas ações desenvolvidas com a Educação Contextualizada. Uma proposta educativa realizada em rede, como é o caso da RESAB. E, cujas possibilidades para a formação de uma nova geração de profissionais, não somente na Educação, mas em todas as áreas do saber técnico-científico, tornarem-se aptos a pensar e desenvolver projetos de desenvolvimento pautados na 'Convivência'. Novas possibilidades para que estes profissionais reelaborem seus discursos e práticas e, por meio do poder da imagem, resignifiquem as visibilidades sobre o sertão semiárido, reapresentando-o como o sertão possível. 


\section{REFERÊNCIAS}

ALBUQUERQUE Jr., Durval Muniz. A Invenção do Nordeste e outras Artes. Recife/PE: FNJ, Ed. Massangana; São Paulo: Cortez, 1999.

ALMEIDA, Maria Geralda de. Fronteiras, Territórios e Territorialidades. In: Revista da ANPEGE. Ano 2, n. 2. p. 103-114, 2005.

Em busca do poético do sertão. Revista Espaço e Cultura. n n 6, p.:35-45, 1998

BONNEMAISON, Joel. Viagem em torno do território. In: CORREA R. ROSENDHAL, Z. (Org.). Geografia cultural. Rio de Janeiro: EdUERJ, 2002.

BRANCO, Samuel Murgel. Caatinga: paisagem e o homem sertanejo. $5^{\text {a }}$ edição. São Paulo: Moderna, 1994. (Coleção Desafio)

BRASIL. Ministério do Meio Ambiente. Secretaria de Recursos Hídricos. PAN-Brasil: Programa de ação Nacional de Combate à Desertificação e Mitigação dos Efeitos da Seca - edição comemorativa 10 anos da CCD - Brasília: MMA/SRH, 2004.

CARVALHO, Luzineide Dourado. Natureza, Território e Convivência: Novas Territorialidades no Semiárido Brasileiro. Jundiaí: Paco Editorial, 2012.

CUNHA, Euclides. Os sertões. Campanha de Canudos. Rio de Janeiro: Editora Francisco Alves, 1991.

FAVERO, Celso Antonio. Semiárido: fome, esperança e vida digna. Salvador (BA): EDUNEB, 2002.

HEIDEGGER, Martin. Todos nós. Ninguém: um enfoque fenomenológico do social. Apresentação e Introdução, notas e epilogo Solon Spanodius; tradução e comentários Dulce Critelli. São Paulo: Moraes LTDA, 1981.

MARTINS, Josemar da Silva e REIS, Edmerson Santos. Proposta político-pedagógica da RESAB: A convivência com o semiárido como norteadora do processo educacional no semiárido brasileiro (Rascunho-manifesto em andamento). In: Secretaria Executiva da RESAB. Anexo 3.Relatório Final da Consultoria COOPERFAJ/UNICEF- 2004- 2004. Juazeiro (BA)RESAB, 2004.

MENDES, Geisa Flores. Sertão se traz na alma? Território/lugar sertão nas filigranas da memória e das representações sociais. 2009. Tese (Doutorado em Geografia). Universidade Federal de Sergipe. Núcleo de Pós-Graduação em Geografia/NPGEO. São Cristóvão, Sergipe, 2009. 
REIS, Edmerson dos Santos. Educação para a Convivência com o Semiárido: Desafios e possibilidades. In: Semiárido Piauiense: Educação e Contexto. INSA. Campina Grande: 2010.

RESAB. REDE DE EDUCAÇÃO DO SEMIÁRIDO BRASILEIRO. Diretrizes da Educação para a Convivência com o Semiárido Brasileiro. Juazeiro - BA: Selo Editorial RESAB, 2006.

REDE DE EDUCAÇÃO DO SEMIARIDO BRASILEIRO. Secretaria Executiva da RESAB. Projeto inclusão, universalização e qualidade da educação no semiárido brasileiro (2004). Juazeiro (BA), 2004.

SANTOS, Juracy Marques dos. Ecologia de homens e mulheres do semi-árido. In: SANTOS, J.M (org). Ecologia de homens e mulheres do semi-árido. Paulo Afonso (BA): Editora Fonte Viva, 2005.

SANTOS, Milton. Técnica, espaço, tempo: globalização e meio técnico - cientifico Informacional. São Paulo: Editora Hucitec, 1994.

SENA, Rosiane Rocha Oliveira. O Semiárido na pauta dos livros didáticos: antigas abordagens e novas perspectivas. Juazeiro: UNEB/DCH III, 2012.

Recebido em: 22 de março de 2014.

Aceito em: 10 de abril de 2014. 